\title{
Duodenal obstruction following papillary stenosis: a rare complication after endoscopic sphincterotomy
}

An 80-year-old man was admitted for abdominal pain and jaundice. Abdominal computed tomography and endoscopic retrograde cholangiopancreatography (ERCP) revealed an impacted bile duct stone in the duodenal papilla with biliary and pancreatic duct dilatation. We safely performed an endoscopic sphincterotomy (EST) and stone extraction. Eighteen months later, the patient was readmitted with jaundice. ERCP showed retraction of the duodenal papilla with stenosis of the biliary and pancreatic duct orifices ( $\bullet$ Fig. 1 ).

We carried out biliary balloon dilatation with stent placement and pancreatic sphincterotomy for the stenosed biliary and pancreatic orifices, respectively. The patient then underwent repeat ERCPs with balloon dilatation and stent placement at 3-month intervals for biliary orifice stenosis. During the follow-up period, retraction of the duodenal papilla progressed and the duodenal lumen at the papillary level began to narrow. At 2 years after the first admission, the patient began to have sustained vomiting. A contrast study showed duodenal obstruction at the papillary level ( Fig. 2). We carried out repeated balloon dilatation for treatment of the duodenal obstruction ( Fig. 3 ). However, the duodenal obstruction continued to worsen, and, eventually, the duodenoscope could not reach the papillary level ( $\bullet$ Fig. 4). Owing to the patient's clinical condition, he was not able to undergo surgical treatment; he finally died from biliary sepsis.

Papillary stenosis is one of the long-term complications of EST, with an incidence ranging between $1.9 \%$ and $2.7 \%$ [ 1 - 3]. Its suggested pathogenesis includes previously inadequate division of the sphincter muscle, direct thermal injury, and genetic factors such as keloid scars $[1,4,5]$. Our patient not only had papillary stenosis but also subsequent duodenal obstruction. Of course we performed a papillary pathologic examination with multiple forceps biop-

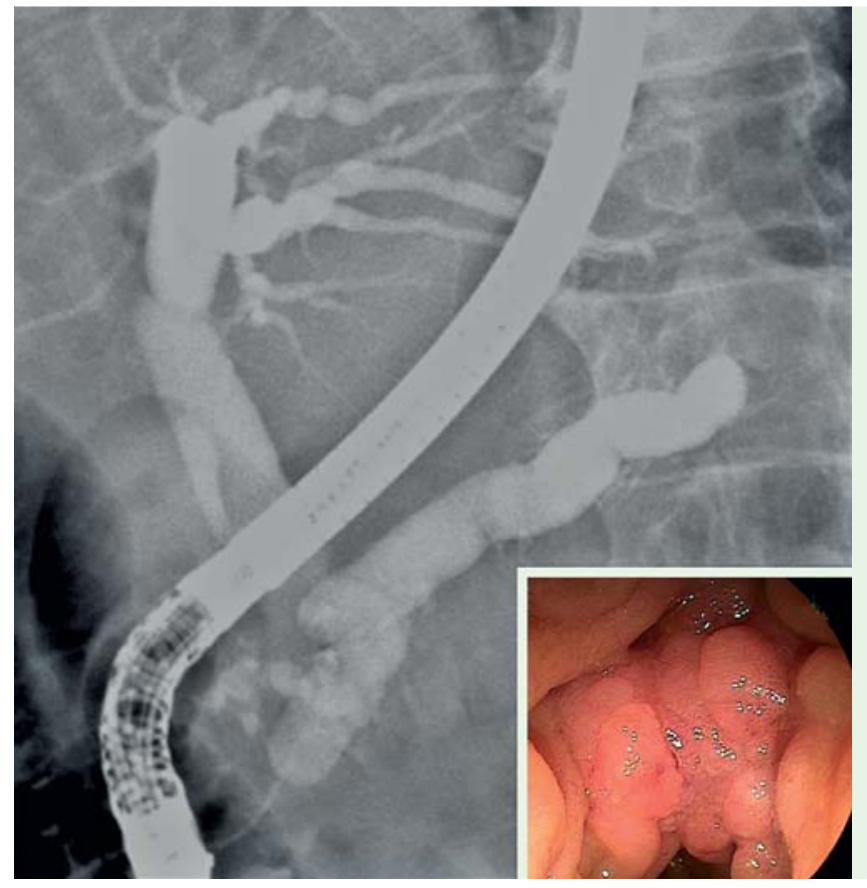

Fig. 1 Endoscopic retrograde cholangiopancreatography (ERCP) showing retracted duodenal papilla with nodular change (inset) and dilatation of the biliary and pancreatic ducts due to papillary stenosis.

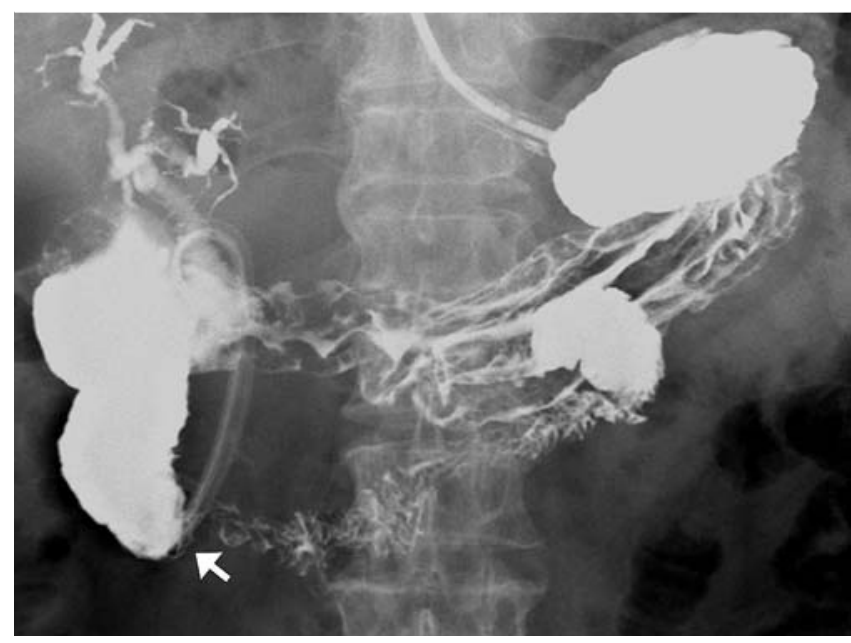

Fig. 2 Contrast study with Gastrografin showing luminal obstruction in the second portion of the duodenum at the papillary level (arrow).

sies during the ERCP sessions, which enabled us to rule out malignant stricture. Although it is difficult to give an exact explanation of which additional potential pathogenic factors might be involved in a rare case, we suggest that the extensive inflammation of the duodenal papilla due to the impacted stone may have had a role in the marked and progressive scarring, leading to development of papillary stenosis and subsequent duodenal obstruction.

Competing interests: None

Endoscopy_UCTN_Code_CPL_1AK_2AZ 

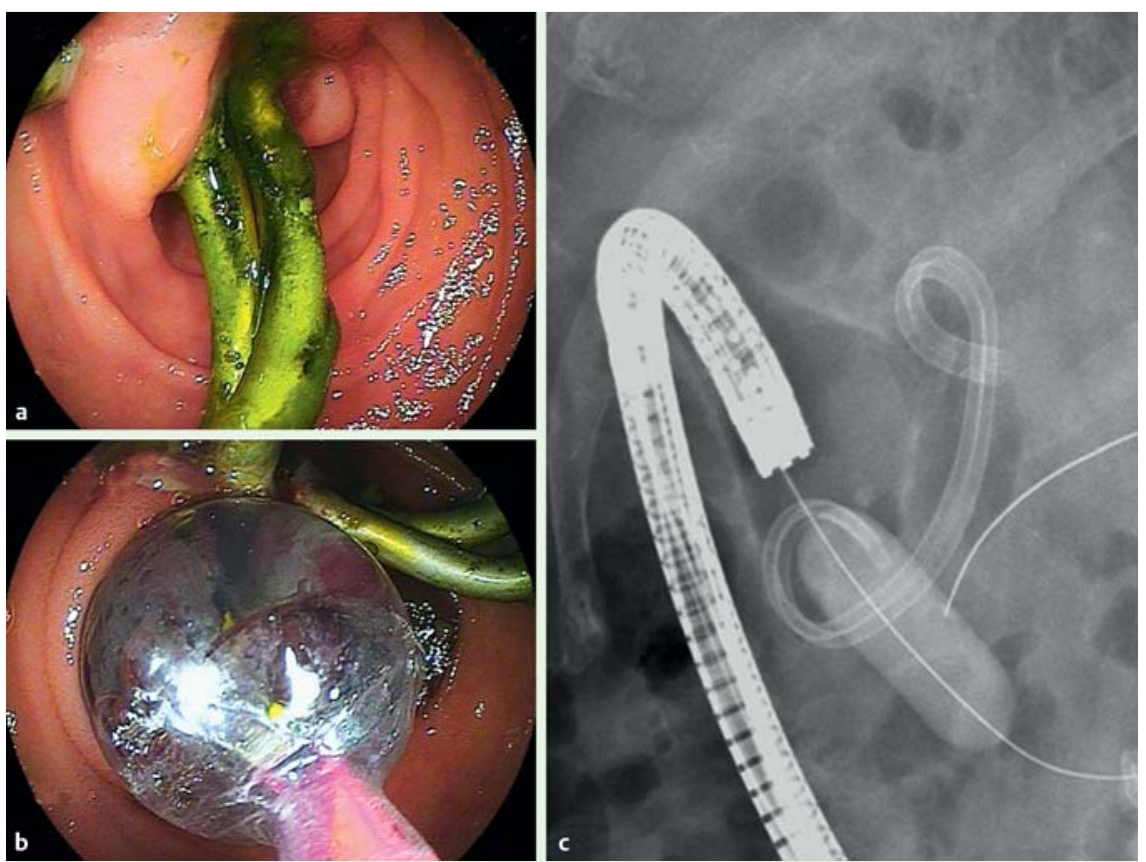

Fig. 3 a Duodenoscopy showing luminal obstruction of the duodenum at the papillary level. Previously inserted biliary plastic stents are seen. $\mathbf{b}, \mathbf{c}$ Balloon dilatation was performed for treatment of the duodenal obstruction.

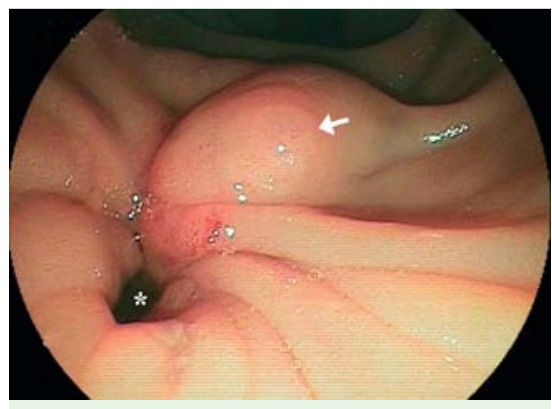

Fig. 4 ERCP duodenoscopic view showing a duodenal luminal obstruction with contracted mucosal folds (asterisk) and a prominent minor papilla (arrow).

\section{J. M. Cha, J. I. Lee}

Department of Internal Medicine, Kyung Hee University East-West Neo Medical

Center, Seoul, Korea

\section{References}

1 Hawes RH, Cotton PB, Vallon AG. Follow up of 6-11 years after endoscopic sphincterotomy for stones in patients with prior cholecystectomy. Gastroenterology 1990; 98: $1008-1012$

2 Prat F, Malak NA, Pelletier $G$ et al. Biliary symptoms and complications more than 8 years after endoscopic sphincterotomy for choledocholithiasis. Gastroenterology 1996; 110: 894-899

3 Veldkamp MC, Rauws EA, Dijkgraaf MG et al. Iatrogenic ampullary stenosis: history, endoscopic management, and outcome in a series of 49 patients. Gastrointest Endosc 2007; 66: 708-716

4 Bourke MJ, Elfant AB, Alhalel R et al. Sphincterotomy-associated biliary strictures: features and endoscopic management. Gastrointest Endosc 2000; 52: 494-499

5 Veldkamp MC, Rauws EA, Dijkgraaf MG et al. Iatrogenic ampullary stenosis: history, endoscopic management, and outcome in a series of 49 patients. Gastrointest Endosc 2007; 66: 708-716

\section{Bibliography}

DOI 10.1055/s-0030-1255975

Endoscopy 2010; 42: E342 -E343

(c) Georg Thieme Verlag KG Stuttgart · New York . ISSN 0013-726X

\section{Corresponding author}

Kyung Hee University

East-West Neo Medical Center

Sangil-dong Gangdong-gu

Seoul 134-090

Korea

Fax: +82-2-440-6295

krjoo@khu.ac.kr 